\title{
Morfología del rromané1-lengua de los gitanos- en un cuento tradicional (paramíchi)
}

\author{
Gastón F. Salamanca Gutiérrez*
}

\section{Resumen}

Este artículo presenta las características más relevantes de la morfología del rromané hablado en Chile, a través de la segmentación morfológica de un cuento tradicional. Luego de la introducción, se presentan algunos aspectos relevantes de la fonología y morfología de la lengua gitana. Específicamente, se presentan los fonemas segmentales, con sus respectivas realizaciones alofónicas y ejemplos para cada uno de ellos; la estructura silábica, también con ejemplos; y los casilleros que se despliegan en las clases de palabra sustantivo y verbo, con sus respectivos morfemas instanciadores. El punto siguiente, el más extenso y que constituye el foco de este trabajo, contiene dos versiones del cuento: una, con el texto en rromané y español, dispuesto en dos columnas; y otra, con el cuento dividido en 152 enunciados (segmentados morfológicamente). Bajo cada uno de estos enunciados, se dan el significado de cada morfema y una traducción semilibre.

Palabras clave: gitanos, Rromané, lengua gitana, cuentos gitanos, morfología del Rromané.

\section{Romani Morphology in a traditional folktale (paramíchi)}

\begin{abstract}
This article presents the most relevant morphological features of the Romani spoken in Chile through the morphological segmentation of a traditional tale. Following the introduction, some important phonological and morphological aspects of the Gipsy language are presented. Specifically, we present the segmental phonemes and examples for each of them; the syllabic structure, also with examples; and the slots which are displayed in the word classes nouns and verbs, with their respective filler morphemes. The next point, the most extensive one and the focus of this work, contains two versions of the tale: one with the text both in Romani and Spanish displayed in two parallel columns; and the other containing the same tale divided into 152 statements (morphologicaly segmented). Under each statement, the meaning of each morpheme and a semi-free translation are given.
\end{abstract}

Keywords: gypsies, Romani, gypsy language, gypsies folktales, Romani morphology.

1 Para la escritura de las palabras en rromané, utilizamos aquí la grafía propuesta por Salamanca y Lizarralde (2008).

* Doctor en Lingüística. Universidad de Concepción, Concepción, Chile. gaston.salamanca@gmail. com 


\section{Introducción}

Este artículo complementa mis trabajos etnográficos y lingüísticos sobre los gitanos rrom de Chile 2 . Su objetivo es describir el aspecto morfológico de un cuento tradicional (paramíchi). Este texto fue recogido en la ciudad de Concepción, Chile, utilizando para ello el modus operandi clásico empleado en la lingüística de campo ${ }^{3}$. Los gitanos que colaboraron en el relato y procesamiento de los textos fueron Yane Nicolich, Yoni Nicolich, Bangó Pantich y Chirilo Patich ${ }^{4}$. El chequeo de la información se realizó en la propia carpa de los informantes, con los gitanos que concurrían a observar estas sesiones de trabajo, más otros colaboradores que estaban radicados en Concepción o estuvieron de paso por esta ciudad.

Dada la extensión del paramíchi ('cuento'), no hemos incluido aquí un detalle de los aspectos teórico-metodológicos utilizados para el análisis morfémico, pero valga decir que éstos fueron extraídos básicamente del descriptivismo norteamericano, tal y como es presentado y aplicado, entre otros, por Nida (1949[1946]), Hockett (1958), Gleason (1960), Elson y Pickett (1964), Samarin (1967), Pickett (1980), Merrifield (1987) y Pike y Pike $(1991)^{5}$.

Estimamos que esta presentación constituye un aporte a los estudios de la lingüística en general y de la romística ${ }^{6}$ en particular, en la medida que, junto con mostrar las características más prominentes de la morfología del rromané hablado en Chile, permite visualizar nuevas investigaciones en este campo ${ }^{7}$.

2 Una información detallada sobre los aspectos etnográficos, lingüísticos, y sobre la vitalidad de la lengua y cultura gitanas en Chile, se encuentra en Salamanca y González (1999), González y Salamanca (2001), Salamanca (2003, 2004a, 2004b, 2004/2005, 2006 y 2008) y Lizarralde y Salamanca (2010).

3 Cada texto se grabó a velocidad normal de relato (primero en rromané, y luego en castellano); después, el texto se grabó a velocidad lenta (el informante escuchó el texto a velocidad normal, se detuvo en cada enunciado mínimo con sentido completo, y lo reprodujo a velocidad lenta de grabación); finalmente, el informante escuchó el texto a velocidad lenta y lo tradujo palabra a palabra.

4 Para la selección de estos colaboradores, tuvimos presentes las recomendaciones contenidas en Samarin (1967).

5 También tuvimos a la vista el texto de Matthews (1974) Morphology: an introduction to the theory of word-structure .

6 Romística es el término que se ha acuñado recientemente para referirse a los estudios sobre la lengua y cultura gitanas.

7 Una de ellas se sugiere en el apartado Conclusiones.

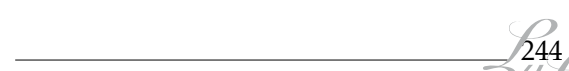




\section{La lengua gitana ${ }^{8}$}

Los gitanos rrom de Chile llaman a su lengua rromané jorajané. Hablan esta lengua en todas las labores tradicionales e incluso cuando está presente un galló ('persona no gitana').

El rromané se opone al (ga)llikané (lengua de los gallé ('personas no gitanas')) y al ludár -o boyás- (dialecto rumano arcaico que hablan algunos gitanos que viven en Santiago de Chile). La interacción entre los gitanos del grupo rrom y los gitanos del grupo ludár se produce sólo en español, pues, en general, los rrom no hablan ludár y viceversa.

\subsection{Fonemas segmentales y estructura silábica}

De acuerdo con González y Salamanca (2001), los fonemas del rromané hablado en Chile son treinta. De éstos, cinco son vocales: /a, e, i, o, u/; veintitrés son consonantes: oclusivas $/ \mathrm{p}, \mathrm{p}^{\mathrm{h}}, \mathrm{t}, \mathrm{t}^{\mathrm{h}}, \mathrm{k}, \mathrm{k}^{\mathrm{h}}, \mathrm{b}, \mathrm{d}, \mathrm{g} /$, fricativas /f, v, s, z, x/, africadas $/ \mathrm{t}$, $\mathrm{d}_{3}, \mathrm{tf}^{\mathrm{h}} /$, nasales / $\mathrm{m}, \mathrm{n}, \mathrm{n} /$, lateral / $/ \mathrm{y}$ vibrantes / $\mathrm{r}, \mathrm{r} /$; y dos son semiconsonantes: /j, w/.

Presentamos ejemplos para cada uno de ellos. Vocales: /a/: /t far/ 'pasto'; /e/: /tfer/ 'casa'; /i/: /t fir/ 'hormiga'; /o/: /tfor/ 'barba'; /u/: /tfu'ri/ 'cuchillo'. Consonantes: /p/: /paj/ 'agua';/ph/:/pha'baj/ 'manzana';/b/l /baj/ 'manga'; /t/: /ta/ 'y'; /th/: /thaw/ 'hilo'; /d/: /dad/ 'padre'; /k/: /kat/ 'tijeras'; /kh/: /kham/ 'sol'; /g/: /gat/ 'camisa'; /f/: /'fala/'gracias'; /v/: /va/ 'mano'; /s/: /sa/ 'todo'; /z/ /'zano/ 'dividir en partes iguales'; /x/: /'xarkuma/ 'cobre'; /tf/: /t $\mathrm{far} /$ 'pasto'; /dz/: /dzal/ '(él) va'; $/ \mathrm{t} \mathrm{h}^{\mathrm{h}} / \mathrm{:} / \mathrm{t} \mathrm{t} \mathrm{f}^{\mathrm{h}}$ adaw/ '(yo) estoy vomitando'; $/ \mathrm{m} /:$ /mak/ 'mosca'; /n/: /nak/ 'nariz'; /n/: /'nano/ (un nombre propio); /1/: /la'tfo/ 'bueno'; /r/: /raj/ 'jefe'; /r/: /ra/ 'pedo'. Semiconsonantes: /j/: /jag/ 'fuego'; /w/: /wa/ 'ese'.

8 Los aspectos que se mencionan aquí constituyen un resumen de las características más importantes de la fonología y morfología nominal y verbal del rromané hablado en Chile, los cuales se contienen en algunos de nuestros trabajos anteriores. 
Las posibilidades silábicas en esta lengua son las siguientes:

\begin{tabular}{|c|c|c|}
\hline 1. V & /e/ & 'la' (artículo femenino) \\
\hline 2. VC & /arno/ & 'huevo' \\
\hline $\mathrm{VSc}$ & /ai.di/ & '¡vamos!' \\
\hline 3. $\mathrm{CV}$ & /na trin/ & 'hoja' \\
\hline $\mathrm{ScV}$ & /wa/ & 'eso' \\
\hline 4. CVC & /t Tar/ & 'pasto' \\
\hline CVSc & /nai/ & 'agua' \\
\hline $\mathrm{ScVC}$ & /iag/ & 'fuego' \\
\hline $\mathrm{ScVSc}$ & /iiw/ & 'nieve' \\
\hline 5. CVCC & /bucs/ & 'año' \\
\hline 6. CCV & /ali.bo/ & 'barro' \\
\hline $\mathrm{CScV}$ & /ilnja/ & 'nueve' \\
\hline 7. CCVC & trin/ & 'tres' \\
\hline $\mathrm{CScVC}$ & /riat/ & 'noche' \\
\hline $\mathrm{CScVSc}$ & /bjaw/ & 'casamiento' \\
\hline
\end{tabular}

Este nivel lingüístico entrega evidencias del bilingüismo subordinado -donde el rromané es la lengua subordinante- que poseen los gitanos de Chile ${ }^{9}$. Esto se aprecia, por ejemplo, en la entonación que caracteriza a los gitanos cuando hablan español y en cómo pronuncian algunas palabras del léxico hispánico. Con respecto a este último punto, tres fenómenos son frecuentes:

a) Epéntesis de nasal velar [y], en el contexto [V.gl]; de modo que una palabra del español como "iglesia" se realiza habitualmente entre los gitanos como [in'glesja]. Esto ocurre porque en rromané la mayoría de las palabras con la secuencia [gl] en contexto intervocálico está precedida por una nasal velar.

b) Alternancia de la semivocal [u] con el sonido fricativo labiodental [v]; de modo que algunas palabras del español como "auto", "pausa" y "Arauco" se realizan habitualmente entre los gitanos como ['avto],

9 Dos características que presenta este bilingüismo son las siguientes: a) la primera lengua que adquieren los niños es el rromané; y b) existe entre los gitanos una actitud muy positiva hacia su lengua. De hecho, hablan sólo rromané cuando interactúan con otros gitanos rrom. El español sólo lo utilizan cuando su uso es imprescindible para comunicase con algún galló o algún gitano boyás.

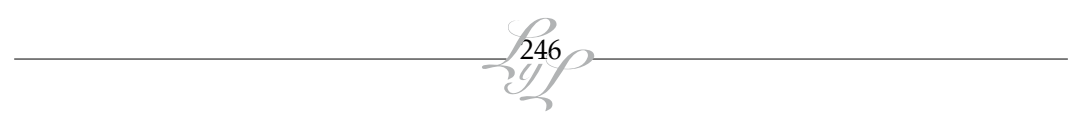


['pavsa] y [a'ravko], respectivamente. Esto se debe a que en rromané esta misma alternancia se produce en posición de coda silábica.

c) Realización vibrante múltiple plena ${ }^{10}$-uvular o alveolar- del fonema /r/; de modo que palabras como "perro" y "cigarro" se realizan siempre entre los gitanos como ['pero] (o ['pero]) y ['sigaro] (o [si'garo]). Esto ocurre porque en rromané las realizaciones de este fonema son, precisamente, la vibrante múltiple alveolar $[\mathrm{r}]$ y la vibrante múltiple uvular [R], con exclusión de variantes con escasa vibración o con grados de fricción/aproximantización, como es frecuente en el habla coloquial del español de Chile.

Estas evidencias, entre otras, muestran que el sistema fónico segmental del rromané interfiere de manera importante en el español hablado por los gitanos de Chile ${ }^{11}$. Si se suman estas evidencias a aquéllas provenientes de otros niveles lingüísticos y al mantenimiento de otros aspectos culturales tradicionales, es plausible sostener que la lengua y cultura gitanas poseen en Chile una gran vitalidad (Salamanca, 2004 2005; Salamanca y Rodríguez, 2009).

\subsection{Morfología}

\subsubsection{Morfología de ítemes tradicionales (temáticos) y no tradicionales (atemáticos)}

Los lingüistas cuyo foco es el rromané dividen el estudio de la morfología de esta lengua en morfología de ítemes tradicionales (llamada también "temática" (Hancock, 1993: 20)) y morfología de ítemes adquiridos en épocas más recientes (llamada también "atemática"). Sobre el particular, Grant señala:

The most important distinction to be made in Romani is that between thematic and athematic grammar. Stem formation, derivational and some inflectional morphology in certain dialects (eg. Past participle and affixes facilitating adoption of loan verbs) separate inhereted words or old loans (pre-European

10 Por "vibrante múltiple plena" entendemos aquí una realización de / $\mathrm{r}$ / como la que se produce en el español de Buenos Aires.

11 Así como en Chile se ha acuñado la expresión "castellano mapuchizado", para señalar las características peculiares del español hablado por los mapuches; podemos hablar aquí de un "castellano rromaneizado", para señalar las características del español hablado por los gitanos rrom. 
words and some early Greek loans) from new loans. Thus Vlax dialects make a distinction between thematic morphology and athematic morphology. Athematic morphology applies to loan words and derives largely from Greek. (Grant, 1994: 5)

De acuerdo con nuestros análisis de la morfología nominal y verbal del rromané, esta distinción es pertinente para el rromané jorajané de Chile.

\subsubsection{Morfología del Sustantivo ${ }^{12}$}

Los sustantivos en rromané de Chile se construyen de acuerdo con la siguiente fórmula tagmémica: Un casillero "núcleo nominal", que es instanciado por un tema nominal; más los casilleros de "género", "caso complementario", "número" y "caso", que son instanciados por morfemas que indican estas funciones. Los casilleros obligatorios en la flexión son los de número y caso. El casillero de género se instancia morfémicamente en los sustantivos animados, cuando es posible un contraste.

Un ejemplo de la extensión máxima de esta fórmula es la palabra "rromiénchar" ('con las gitanas'). Aquí, el núcleo nominal es instanciado por el tema nominal "rrom-" ('gitano'); el casillero de género lo instancia el sufijo "-i" ('femenino'); el casillero de caso complementario es instanciado por el sufijo "-é" ('Sufijo Indicador de Caso Complementario'); el casillero de número lo instancia el sufijo "-n" ('plural'); y el casillero de caso gramatical es instanciado por el sufijo "-char" ('instrumental'). Así:

\begin{tabular}{|c|c|c|c|c|}
\hline $\begin{array}{c}\text { Núcleo } \\
\text { Nominal }\end{array}$ & Género & Caso compl. & Número & Caso \\
\hline Tema nominal & Morf. de gén. & SICC ${ }^{13}$ & $\begin{array}{c}\text { Morf. de } \\
\text { núm. }\end{array}$ & $\begin{array}{c}\text { Morf. de } \\
\text { caso }\end{array}$ \\
\hline rrom- & $-\mathrm{i}$ & -é & -n & -char \\
\hline
\end{tabular}

El tema nominal contiene un casillero "centro" obligatorio, instanciado por una raíz sustantiva o adjetiva, y un casillero de derivación instanciado por un sufijo derivacional. Un ejemplo de este caso es la palabra "barbalipé" ('riqueza'), donde una raíz adjetiva ("barbal-" ('rico'))

12 Aquí seguimos las fórmulas que se utilizan en la escuela tagmémica de análisis gramatical (Cfr. Elson y Pickett, 1964).

13 Este es el Sufijo Indicador de Caso Complementario (Cfr. Salamanca, 2003).

248 
instancia el casillero "centro", y un sufijo ("-ipé") instancia el casillero "derivación".

\begin{tabular}{|c|c|}
\hline Centro & Derivación \\
\hline Raíz adjetiva / tema nominal & afijo derivacional \\
\hline barbal- & -ipé \\
\hline
\end{tabular}

El tema nominal "rromorró" ('gitanito') es otro ejemplo. Aquí se aprecia que éste se construye con la raíz "rrom-" ('gitano'), más el sufijo diminutivo "-orr" que instancia el casillero "derivación"14.

\subsubsection{Morfología del Verbo ${ }^{15}$}

La construcción de los verbos en rromané se despliega en dos niveles: nivel de la palabra y nivel de la frase. En el nivel de la palabra, la fórmula tagmémica contiene un casillero "núcleo verbal", instanciado por un tema verbal; y dos casilleros marginales de "tiempo aspecto" y "persona número", instanciados por morfemas que señalan sincréticamente estas categorías gramaticales.

Por ejemplo, la palabra "dikhlém" ('vi') tiene un tema verbal "dikh" ('ver'), que instancia el casillero "núcleo verbal"; un morfema "-1", que instancia el casillero de "tiempo y aspecto" ('pretérito perfecto', en este caso), y un morfema "-ém", que instancia el casillero de "persona y número"' ('primera singular', en este caso).

Así:

\begin{tabular}{|c|c|c|}
\hline Núcleo Verbal & Tiempo y Aspecto & Persona y Número \\
\hline Tema verbal & Morf. de tpo. / asp. & morf. de pers. / núm. \\
\hline dikh- & -1 & -ém \\
\hline
\end{tabular}

En el nivel de la frase, una forma verbal rromané se construye con un casillero "tiempo" obligatorio, instanciado por una partícula de futuridad; y un casillero "cabeza", también obligatorio, instanciado por un verbo (en tiempo presente). Por ejemplo, la frase "ka cheráu" ‘voy a hacer' tiene una partícula de futuridad "ka", que instancia el casillero

14 El sufijo final corresponde a la marca de género (masculino en este caso). Salamanca (2006 y 2008) presenta los paradigmas de declinación de los sustantivos temáticos y atemáticos, respectivamente.

15 Salamanca (2004b) presenta los paradigmas de conjugación de los verbos temáticos. 
de tiempo; más la palabra "cheráu" ('estoy haciendo'), que instancia el casillero "cabeza".

\begin{tabular}{|c|c|}
\hline Tiempo & Cabeza \\
\hline Partícula de futuridad & verbo \\
\hline ka & cheráu \\
\hline
\end{tabular}

En rromané, se distinguen tiempos básicos y tiempos derivados. Los tiempos básicos son el presente y el pretérito perfecto; los derivados, el pretérito imperfecto, el pluscuamperfecto y el futuro. Los dos primeros tiempos derivados se obtienen al agregar el sufijo "-a"16 a las formas de presente y pretérito perfecto, respectivamente. El futuro, por su parte, tal como lo hemos señalado en el párrafo precedente, se obtiene al anteponer la partícula de futuridad a la forma del presente.

El verbo "tener" se construye con la forma del verbo "ser" en tercera persona, más un clítico en caso acusativo.

\section{Análisis morfológico}

\subsection{Consideraciones preliminares}

Como foco de este trabajo, presentamos la segmentación morfológica de un extenso cuento gitano (paramíchi). En primer lugar, se presenta el texto completo, no segmentado, en su versión en rromané y en español. En seguida, se presenta el análisis morfológico del texto de acuerdo con el siguiente formato: la primera línea presenta la segmentación morfémica del texto; la segunda, el significado de cada morfema que compone la palabra; y la última, una traducción semilibre ${ }^{17}$.

Conviene advertir que la numeración de los enunciados en el análisis morfológico sólo tiene una finalidad práctica: hacer expedita la búsqueda de los ejemplos que se dan en el apartado Conclusiones.

\subsection{Versión no segmentada en rromané y español}

Presentamos a continuación el paramíchi, en sus versiones en rromané y español. Cuando la mejor comprensión del texto en español así lo requirió, pusimos entre paréntesis cuadrados algunos enunciados.

16 Hemos denominado a este morfema Sufijo Preterizador de Tiempos Básicos (SPTB).

17 Los préstamos del español se subrayan y escriben de acuerdo con la grafía de esta lengua.

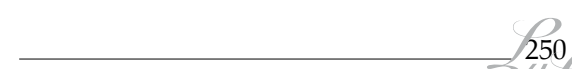




\section{0 rrom ta o gigante}

Sáya pe g(ay)á barí riat yek rromorró ta yek rromiorrí.

Von sáya len but chavrré.

Chorrorré, (i)nai len charícha, (i)nai len níso.

O rrom cheréla but páile.

Ondaká, koté sáya o cháro ta e rakhlie charóki.

Sa e gallé and o fóro

chúden barrénchar and e yek phabái.

Kom peravéla e phabái, zinilape con e rakhli e charóki.

Ondaká, avél o chavrró kai po dad,

-" ¡dáde, dáde!, jchúde tu dáde!"

-"Na bre, me cheráu paile te jan".

Ondaká, o rrom lia o chokáno ta chudiá, ta peradá e phabái.

Ondaká, aviló o cháro ta sa léke gallé léte, ta puchléle:

-" ¿Tu peradán e phabái?"

-"Eá, manús, me chavrré seá bokhalé, ta goléke peradém la".

-"Truvúl te compañi amén tu".

-"Na, manús, man si man desudúi chavrré".

Ondaká, muklá pe rromiá.

Koté kai o cháro, phen léke:

-"tu pera(v)dán e phabái; tu truvúl te ziní to".

-" Pero sar ka me ziní ma, me, manus; dikhé, man si man desudúi chavrré ta mi rromi".

-"Tu te na zinía to, ka chináu chi korr".

Ondaká, te na mudarén le, zinilpe con e rakliáya.

Koté veséla con o cháro. Jála, piéla, pero inchá léke chavrré merén bokhátar. Ondaká, vov mangél te nasél.

Putarél e ventana ta nasél.

\section{El gitano y el gigante}

Había en esta gran noche un gitanito y una gitanita.

Ellos tenían muchos hijos.

Pobrecitos, no tienen carpita, no tienen nada.

El gitano hacía muchas pailas.

Entonces, ahí estaba el rey y su hija.

Todas las personas en la ciudad están tirando piedras a una manzana. Quien bote la manzana, se casa con la hija del rey.

Entonces, viene el hijo donde su padre, [y le dice]

- "ipapá!, jpapá!, jtira tú papá!"

- "No hijo, estoy haciendo pailas para [poder venderlas y así poder] comer".

Entonces, el gitano tomó el martillo y lo tiró, y botó la manzana.

Entonces, vino el rey y toda su gente donde él, y le preguntaron: - "TTú botaste la manzana?" -"Sí, señor, mis hijos estaban hambrientos, y por eso la boté".

-"Debes acompañarnos".

-"No, señor, yo tengo doce hijos".

Entonces, dejó a su señora.

Allí donde el rey, le dicen:

-"tú botaste la manzana; tú te tienes que casar".

-"Pero cómo me voy a casar, yo, señor; mira, yo tengo doce hijos y mi esposa".

-"Si tú no te casas, voy a cortar tu cuello".

Entonces, para que no lo mataran, se casa con la muchacha.

Ahí se sentaba con el rey. Comía, bebía, pero allá sus hijos mueren de hambre. Entonces, él quiere arrancarse.

Abre la ventana y se arranca. 
Inllarél yek bullorró, kai thovél

pi chéska ta po chokáno.

Inllarél chirál ta marrnó; ta naslótar.

Llelótar and o bosque.

Ondaká, avél o gigante léte.

$O$ gigante mangél te mudarél le.

- "¿So cheré tu katé?Me sem o jefe

katé; asi que me ka mudaráu to”.

- "Pero sar ka mudaré ma,

man si man desudúi chavrré

ta mi rromi".

- "No, truvúl te mudaráu to.

Amén ka cherá yek apuesta.

Koté si yek pechín barí.

Kom chalavéla mai zuralé

and e pechín, ka mudarél yek averé".

$O$ rrom phenél:

- “áko, pero thiára truvúl te cherá e apuesta".

Ondaká, kána llelótar o gigante, o rrom achiló koté kai o barr.

Vov akandá pi chéska ta po chokáno

ta cherdá yek jíu and o barr.

Vov thodá chirál ta marrnó andré

ta uchardá o barr.

Ondaká, al otro día avél o gigante.

-“rroméa: ¿ustilán?

Ka dikhá kom ka mudarél yek averé".

Ondaká, o gigante del yek puñete

and o barr.

Mapál o rrom dia yek puñete.

Akandá chirál o rrom vizái.

Ondaká o rrom phenél:

- "Sorró ka mangáu, tu ka cheré.

Me ni meráu, me sem zuraló".

$O$ gigante phenél:

- "So kaméa mándar, me ka cheráu”.

- “Áko”, o rrom phenél,

"tu ka inllaré man llik inchá

kai si mi rromí,

ta truvúl te de man

yek brécha sunakái”.

Ondaká o gigante inllardá le

ta o rrom achiló barbaló

con pi rromiáya ta con pe chavrrénchar.
Lleva un bolsito, donde coloca

su cincel y su martillo.

Lleva queso y pan; y se escapó.

Se fue al bosque.

Entonces, viene el gigante donde él.

El gigante quiere matarlo.

-“¿Qué haces tú aquí? "Yo soy el jefe

aquí; así es que te voy a matar".

-"Pero cómo me vas a matar,

yo tengo doce hijos

y mi esposa".

- "No, te tengo que matar.

Vamos a hacer una apuesta.

Allí hay una piedra grande.

Quien golpee más fuerte

en la piedra, va a matar al otro".

$\mathrm{El}$ gitano dice:

-"bueno, pero mañana debemos hacer

la apuesta".

Entonces, cuando se fue el gigante,

el gitano se quedó allí en la piedra.

Él buscó su cincel y su martillo

e hizo un hoyo en la piedra.

Puso queso y pan dentro

y tapó la piedra.

Entonces, al otro día viene el gigante [y

le dice]

-“gitano: ¿te levantaste?"

Vamos a ver quien va a matar al otro".

Entonces, el gigante da un puñete

en la piedra.

Después el gitano dio un puñete.

Sacó queso el gitano inteligente.

Entonces el gitano dice:

-"Todo lo que yo desee,

tú lo vas a hacer.

Yo no muero, yo soy fuerte".

$\mathrm{El}$ gigante dice:

- "Lo que quieras de mí,

yo lo voy a hacer".

-"Bueno", dice el gitano,

"tú me vas a llevar hasta allá

donde está mi esposa,

y debes darme

un saco de oro".

Entonces el gigante lo llevó

y el gitano quedó rico

con su mujer y con sus hijos. 


\subsection{Segmentación en morfemas}

$\begin{array}{ll}\text { 1. } s(a ́ y)- & -a \\ \text { ser/haber } & \text { SPTB }^{18}\end{array}$

Había

2. pe $\quad g-\ldots \quad-a-\quad-y-\quad \ldots-a$ bar- $\quad-i \quad$ riat $\rightarrow$ I en DEM. ${ }^{19}$ PROX. $^{20}$ FEM. DEM. grande FEM. noche en esta gran noche

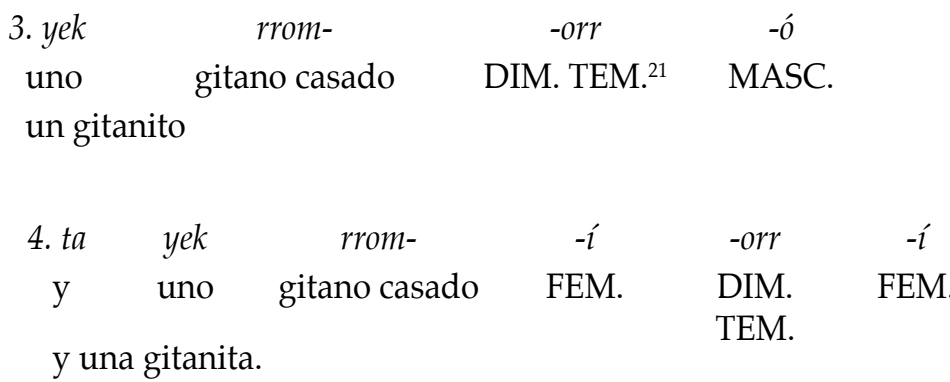

$\begin{array}{ccccc}\text { 5. von } & \text { s(áy)- } & -a & l- & -e n \\ \text { PRON. PERS. 3 PL. } & \text { ser } & \text { SPTB } & \text { PRON. ACUS. } & \text { PL. } \\ & & & 3^{22} & \end{array}$

Ellos tenían

$\begin{array}{lccc}\text { 6. but } & \text { chavrr- } & -e ́ & \searrow \mid \\ \text { mucho } & \text { hijo } & \text { PL. } & \\ \text { muchos hijos. } & & & \end{array}$

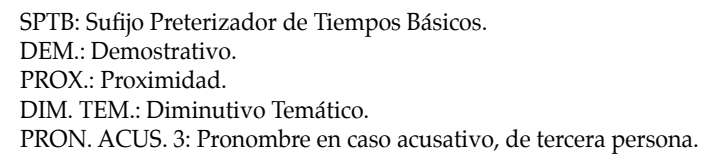




$\begin{array}{lccc}\text { 7. chorr- } & \text {-orr } & -e ́ & \rightarrow 1 \\ \text { pobre } & \text { DIM. TEM. } & \text { PL. } & \\ \text { Pobrecitos, } & & \end{array}$

\begin{tabular}{|c|c|c|c|c|}
\hline 8. (i)nai & l- & $-e n$ & char- & -ích \\
\hline $\begin{array}{l}\text { NEG. } \\
\text { no tien }\end{array}$ & $\begin{array}{l}\text { PRON. ACUS. } 3 \\
\text { carpita, }\end{array}$ & PL. & carpa & DIM. ATEM. ${ }^{23}$ \\
\hline
\end{tabular}

$\begin{array}{llllll}\text { 9. (i)nai } & l- & \text { en } & n i & \text { so } & \searrow \text { I। } \\ \text { NEG. } & \text { PRON. ACUS. } 3 & \text { PL. } & \text { NEG. } & \text { qué } & \end{array}$
no tienen nada.

10. o rrom cher- él -a ART. DEF. MASC. SING. gitano casado hacer 3 SING. SPTB El gitano hacía

\begin{tabular}{|c|c|c|}
\hline 11. but & páil & $-e$ \\
\hline mucho & paila & PL. \\
\hline
\end{tabular}
12. ondaká $\rightarrow 1$ koté s(áy)- $-a \quad$ cháro $\rightarrow 1$ entonces ahí ser SPTB ART.DEF. rey Entonces, ahí estaba el rey MASC. SING.

13. $t a$ e rakhl- $-i$ y ART. DEF. FEM. SING. joven FEM. y la hija 


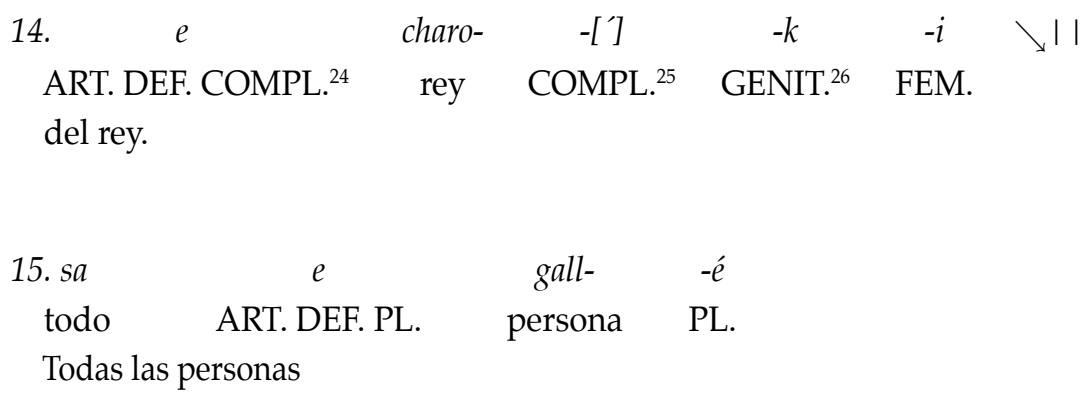

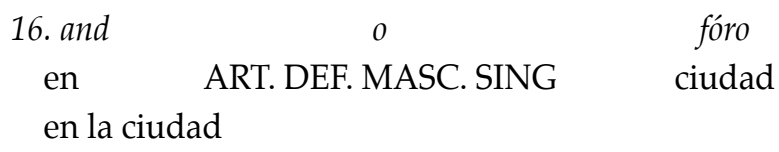

\begin{tabular}{|c|c|c|c|c|c|}
\hline $\begin{array}{l}\text { 17. chud- } \\
\text { tirar }\end{array}$ & $\begin{array}{l}-e n \\
3 \text { PL. }\end{array}$ & $\begin{array}{l}\text { barr- } \\
\text { piedra }\end{array}$ & $\begin{array}{c}-e ́ \\
\text { SICC. }\end{array}$ & $\begin{array}{l}-n \\
\text { PL. }\end{array}$ & $\begin{array}{c}\text {-char } \\
\text { INSTR. }{ }^{28}\end{array}$ \\
\hline
\end{tabular}
18. and
e
yek phabái
en ART. DEF. FEM. SING. uno manzana

a una manzana.
19. kom perav- -él $-a \quad$ e phabái $\rightarrow$ I
quien botar 3 SING. SPTB ART. DEF. manzana FEM.SING.

Quien bote la manzana,

\begin{tabular}{ccccc} 
20. $\begin{array}{c}\text { zin }- \\
\text { casarse }\end{array}$ & $-i$ & $-l$ & $-a$ & $-p e$ \\
se casa & V.T. $^{29}$ & 3SING. & SPTB & REFL. ${ }^{30}$ \\
\hline
\end{tabular}

24 Esta es la forma del artículo definido masculino o femenino cuando está en una frase que es un complemento.

25 COMPL.: (marcador de) Complemento. Equivale al Sufijo Indicador de Caso Complementario, pero en el nivel fónico.

26 GENIT.: Genitivo.

SICC: Sufijo Indicador de Caso Complementario.

INSTR: (Sufijo de caso) Instrumental.

V.T.: Vocal Temática.

REFL: Reflexivo. 


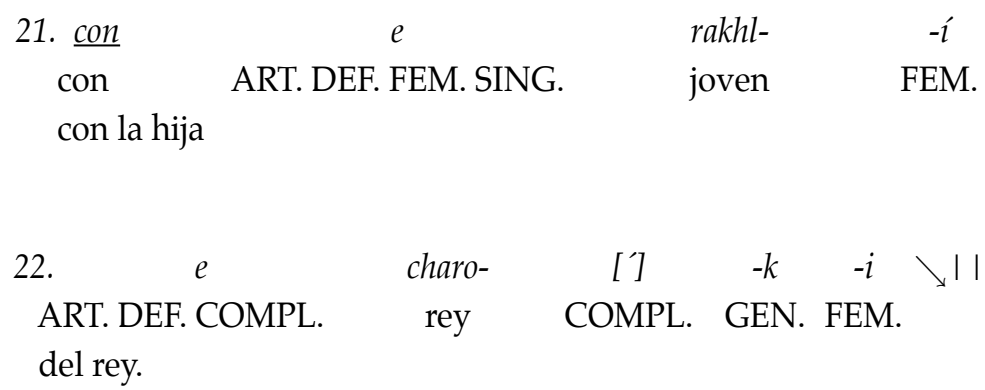
23. ondaká $\rightarrow 1$ av- -él chavrr- ó entonces venir 3SING. ART. DEF. hijo MASC.
Entonces, viene el hijo MASC. SING.

$\begin{array}{lccc}\text { 24. } k a i & p- & -0 & \text { dad } \\ \text { donde } & \text { ADJ. POS.3 SING. }{ }^{31} & \text { MASC. } & \text { papá } \\ \text { donde su papá [y le dice] } & & \end{array}$

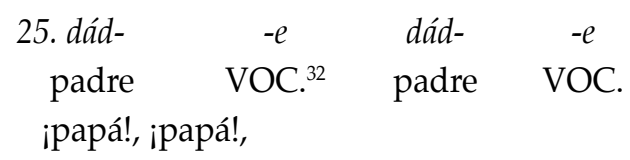
26. chúd- te tu dád- -e tirar 2 SING. PRON. PERS. 2 SING. padre VOC. ¡tira tú papá!
27. na bre
NEG. muchacho

No hijo, 
28. me

cher-

-áu

páil- -e

PRON. PERS. 1 SING.

hacer 1SING. paila PL.

estoy haciendo pailas

29. te

$$
j(a)-
$$

$-n$

NOM. ${ }^{33}$ comer 3 PL.

para [venderlas y así ustedes puedan] comer.
30. ondaká$$
\rightarrow 1
$$
$o$
rrom
entonces
ART. DEF. MASC. SING. gitano casado
Entonces, el gitano
31. $l-\quad-i \quad-a \quad c h$ chokáno tomar P. PERF. ${ }^{34}$ 3SING. ART. DEF. MASC. SING. martillo tomó el martillo
32. ta chud- $-i \quad-a ́ \quad \rightarrow||$
y tirar P. PERF. 3 SING.
y lo tiró,

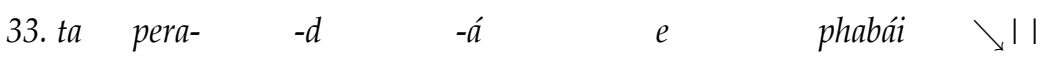
y botar P. PERF. 3 SING. ART. DEF. manzana
y botó la manzana.
FEM. SING

$\begin{array}{lrrccc}\begin{array}{l}\text { 34. ondaká } \rightarrow|| \\ \text { entonces }\end{array} & \text { av(i)- } & -l & -0 ́ & O & \text { cháro } \\ & \text { venir } & \text { P. PERF. } & \text { 3 SING. } & \text { ART. DEF. } & \text { Rey } \\ \text { Entonces, vino el rey } & & & \text { MASC. SING. } & \end{array}$

33 NOM.: Nominalizador.

34 P. PERF.: Pretérito Perfecto. 


$\begin{array}{lccccc}\text { 35. } t a \quad s a & \text { lék- } & -e & \text { gall- } & -e ́ \\ \text { y todo } & \text { ADJ. POS. 3 } & \text { PL. } & \text { gente } & \text { PL. } \\ \text { y toda su gente } & & & & \end{array}$

\begin{tabular}{|c|c|c|}
\hline 36. & $-e$ & -te \\
\hline $\begin{array}{l}\text { PRON. ACUS. } 3 \\
\text { donde él, }\end{array}$ & MASC. & LOC. $^{35}$ \\
\hline
\end{tabular}

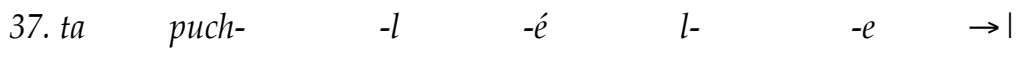 y preguntar P. PERF. 3 PL. PRON. MASC. y le preguntaron: ACUS. 3
38. $\quad$ tu pera(v)- $\quad-d$-án PRON. PERS. 2 SING botar P. PERF. 2 SING. ¿Tú botaste

39. ART. DEF. FEM.SING la manzana?

phabái $\quad$ II
botar

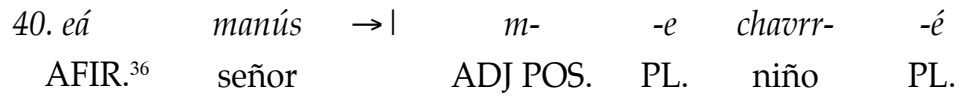
Sí señor, mis hijos 1 SING.

\begin{tabular}{|c|c|c|c|c|}
\hline $\begin{array}{c}\text { 41. s(e)- } \\
\text { ser }\end{array}$ & $\begin{array}{c}-a ́ \\
\text { SPTB }\end{array}$ & $\begin{array}{c}\text { bokh- } \\
\text { hambre }\end{array}$ & $\begin{array}{c}-a l \\
\text { ADJ. }{ }^{37}\end{array}$ & $\begin{array}{l}-e ́ \\
\text { PL. }\end{array}$ \\
\hline
\end{tabular}

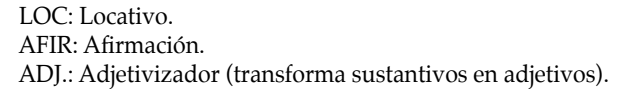




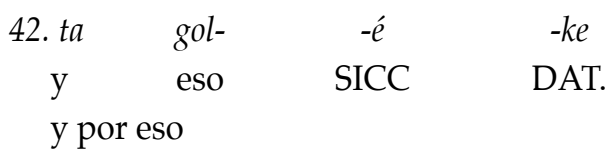

$\begin{array}{lcccc}\text { 43. pera(v)- } & -d & -e ́ m & l- & -a \\ \text { botar } & \text { P. PERF. } & \text { 1SING. } & \text { PRON. } & \text { FEM. } \\ \text { la boté. } & & & \text { ACUS. } 3 & \end{array}$

$\begin{array}{lcccc}\text { 44. truvúl } & \text { te } & \text { kompañ- } & -i & \text { Amén } \\ \text { deber } & \text { NOM. } & \text { acompañar } & \text { V.T. } & \text { PRON. } \\ \text { Debes acompañarnos. } & & & \text { ACUS. 1 PL. }\end{array}$

\begin{tabular}{|c|c|}
\hline 45. na & manús \\
\hline NEG. & Señor \\
\hline
\end{tabular}
46. man s- $\quad-i \quad \operatorname{man}$
PRON. ACUS. 1 SING. $\quad$ ser 3 SING. PRON. ACUS. 1 yo tengo
SING.

$\begin{array}{lcc}\text { 47. desudúi } & \text { chavrr- } & -e ́ \\ \text { doce } & \text { hijo } & \text { PL. } \\ \text { doce hijos. } & & \end{array}$

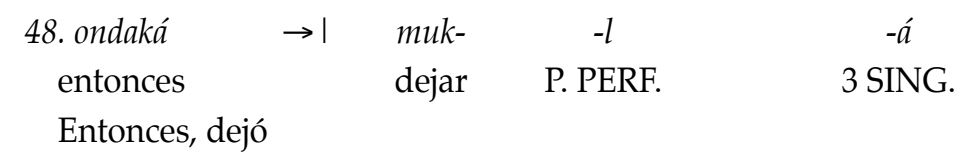


49.

$$
p-\quad \text {-e rrom- }-i \quad-a ́
$$

ADJ. POS. 3 FEM. SING. gitano FEM. SICC

a su señora.

COMPL. ${ }^{38}$

50. koté kai

allí donde

o

cháro $\rightarrow 1$

Allí donde el rey,

ART. DEF. MASC. SING. rey

\begin{abstract}
Alli donde el rey,
\end{abstract}
$\begin{array}{rrccc}\text { 51. ph- } & -e ́ n & l- & -e & -k e \\ \text { decir } & \text { 3 PL. } & \text { PRON. ACUS. 3 } & \text { MASC. } & \text { DAT. }^{39}\end{array}$ le dicen:

52. $t u$

PRON. PERS. 2 SING.

tú botaste

$\begin{array}{ccc}\text { pera }(v)- & -d & -a ́ n \\ \text { botar } & \text { P. PERF. } & \text { 2 SING. }\end{array}$

53.

PRON. PERS. 2 SING.

phabái $\rightarrow$ I

botar

la manzana;

54. tu truvúl te ziní to

PRON. PERS. 2 SING. deber NOM casarse REFLEX. tú tienes que casarte.

$\begin{array}{ll}\text { 55. péro } & \text { sar } \\ \text { pero } & \text { cómo } \\ \text { Pero cómo } & \end{array}$

38 FEM. SING. COMPL.: Femenino Singular en caso Complementario.
39 DAT.: Dativo. 


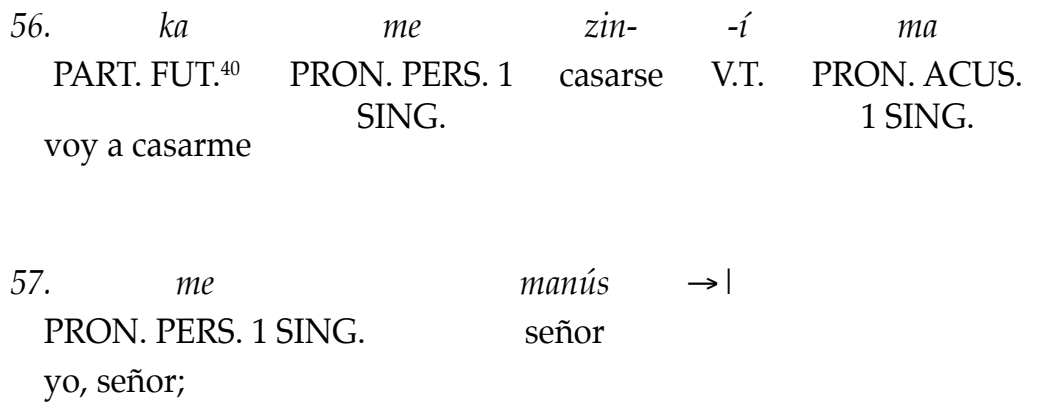

$\begin{array}{lcl}\text { 58. dikh- } & -e ́ & \rightarrow 1 \\ \text { mirar } & \text { 2 SING. } & \\ \text { mira, } & \end{array}$

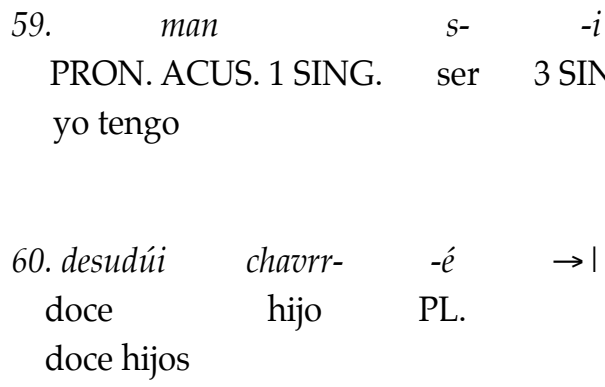

61. $t a \quad m-\quad-i \quad$ rrom- $-i \quad \searrow||$ y ADJ. POS.1SING. FEM. gitano casado FEM. y mi esposa.

62. $t u$

PRON. PERS. 2 SING.

te na Si tú no

40 PART. FUT.: Partícula de Futuridad.

41 Conjunción condicional 


$\begin{array}{lccc}\text { 63. } z \text { in }- & -i & -a & \text { to } \\ \text { casarse } & \text { V.T. } & \text { SPTB } & \text { PRON. ACUS. 2 SING. } \\ \text { te casas, } & & & \end{array}$

64. ka chin -áu ch- $\quad i \quad k o r r$

PART. FUT. cortar 1SING. ADJ. POS. FEM. cuello te voy a cortar el cuello.

2 SING.

\section{5. ondaká $\rightarrow 1$ \\ entonces \\ Entonces,}

66. te na mudar- -én l- $\quad$-e

NOM. NEG. matar 3 PL. PRON. MASC.

para que no lo mataran

ACUS. 3

$\begin{array}{lccc}\text { 67. } z i n- & -i & -l & -p e \\ \text { Casarse } & \text { V.T. } & \text { 3 SING. } & \text { REFL. } \\ \text { se casa } & & & \end{array}$
68. con rakl- $\quad-i \quad-a \quad(y)-a$
con ART. DEF. joven FEM. SICC INSTR.
COMPL.

con la muchacha.

$\begin{array}{lccc}\text { 69. koté } & \text { ves- } & \text { él } & -a \\ \text { ahí } & \text { sentarse } & \text { 3 SING. } & \text { SPTB } \\ \text { Ahí se sentaba } & \end{array}$
70. $\underline{\text { con }}$ o cháro \।I con ART. DEF. MASC. SING. rey con el rey. 


$\begin{array}{cccccccc}\text { 71. } j(a ́)- & -l & -a & t a & p i- & -e ́ l & -a & \rightarrow 1 \\ \text { comer } & \text { 3SING. } & \text { SPTB } & \text { y } & \text { beber } & \text { 3 SING. } & \text { 3 SING. } & \end{array}$
Comía y bebía,

\begin{tabular}{|c|c|c|c|c|}
\hline $\begin{array}{l}\text { 72. péro } \\
\text { pero }\end{array}$ & $\begin{array}{l}\text { inchá } \\
\text { allá }\end{array}$ & $\begin{array}{c}\text { lék- } \\
\text { ADJ. POS. MASC. } 3\end{array}$ & $\begin{array}{l}-e \\
\text { PL. }\end{array}$ & $\begin{array}{l}\text { chavrr- } \\
\text { hijo }\end{array}$ \\
\hline
\end{tabular}

$\begin{array}{lccccc}\text { 73. mer- } & \text {-én } & \text { bokh- } & -a ́ & \text {-tar } \\ \text { morir } & \text { 3 PL. } & \text { hambre } & \text { SICC } & \text { ABLAT. }{ }^{42} & \\ \text { mueren de hambre. } & & & & \end{array}$

74. ondaká $\quad \rightarrow 1$
entonces
Entonces,

$\begin{array}{llc}75 . \quad \text { vov } & \text { mang- } & \text {-él } \\ \text { PRON. PERS. 3 SING. MASC. } & \text { querer } & \text { 3 SING. } \\ \text { él quiere } & & \end{array}$
NOM. arrancar 3 SING. arrancarse.
77. putar- -él ventána abrir 3 SING. ART. DEF. FEM. SING. ventana Abre la ventana

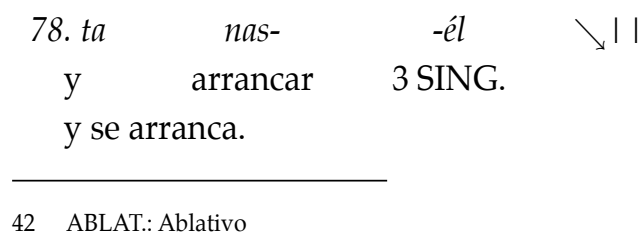



79. inllar- -él yek bull- -orr ó \। llevar 3 SING. uno bolso DIM. TEM. MASC. lleva un bolsito,
80. kai thov- -él p- $\quad-i \quad c h e ́ s k a$ donde colocar 3 SING. ADJ. POS. 3 FEM. Cincel donde coloca su cincel

$\begin{array}{lccc}\text { 81. } t a & p- & -o & \text { chokáno } \\ \text { y } & \text { ADJ. POS. } 3 & \text { MASC. } & \text { martillo } \\ \text { y su martillo. } & \end{array}$

$\begin{array}{lccccc}\text { 82. inllar- } & \text {-él } & \text { chirál } & \text { ta } & \text { marrnó } & \rightarrow \text { | } \\ \text { llevar } & \text { 3 SING. } & \text { queso } & \text { y } & \text { pan } & \\ \text { lleva queso y pan; } & & & & \end{array}$

$\begin{array}{lcccc}\text { 83. ta } & \text { nas- } & -l & -0 ́ & -t a r \\ \text { y } & \text { escapar } & \text { P. PERF. } & \text { 3 SING. } & \text { REFL. } \\ \text { y se escapó. } & & & \end{array}$

$\begin{array}{lccc}\text { 84. } l l(e)- & -l & -o ́ & - \text { tar } \\ \text { ir } & \text { P. PERF. } & \text { MASC. } & \text { REFL } \\ \text { Se fue } & & & \end{array}$
85. and
en
$o$ bósque \II
ART. DEF. MASC. SING. bosque al bosque.

$\begin{array}{ccccc}\begin{array}{c}\text { 86. ondaká } \rightarrow 1 \\ \text { entonces }\end{array} & \begin{array}{c}\text { av- } \\ \text { venir }\end{array} & \begin{array}{c}\text {-él } \\ \text { 3SING. }\end{array} & \begin{array}{c}\text { ART. DEF. } \\ \text { ARSC. SING. }\end{array} & \text { gigante } \\ \text { Entonces, viene el gigante } & & \text { MASC. }\end{array}$




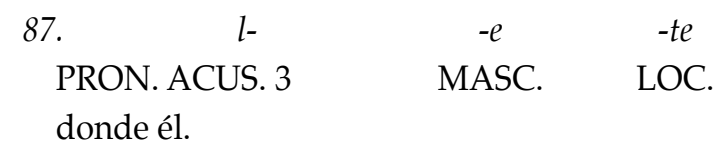

88.

ART. DEF. MASC. SING.

gigante mang- -él

El gigante quiere

gigante querer 3 SING.

$\begin{array}{lcccc}\text { 89. te } & \text { mudar- } & \text { él } & l- & -e \\ \text { NOM. } & \text { matar } & \text { 3SING. } & \text { PRON. } & \text { MASC. } \\ \text { matarlo. } & & & \text { ACUS. } 3\end{array}$
90. so cher- é tu katé qué hacer 2SING. PRON. PERS. 2 SING. aquí ¿Qué haces tú aquí?

$\begin{array}{lcc}91 . \quad \text { me } & \text { s- } & \text {-em } \\ \text { PRON. PERS. 1 SING. } & \text { ser } & \text { 1SING. } \\ \text { Yo soy } & & \end{array}$

92.

$\begin{array}{ccc}0 & \text { jefe } & \text { katé } \rightarrow 1 \\ \text { ART. DEF. MASC. SING. } & \text { jefe } & \text { aquí }\end{array}$

el jefe aquí,

93. me

PRON. PERS. 1 SING.

yo

$\begin{array}{cccc}\text { 94. } \quad k a & \text { mudar- } & -a ́ u & \text { to } \\ \text { PART. FUT. } & \text { matar } & \text { 1 SING. } & \text { PRON. ACUS. } \\ & & & \text { 2 SING. }\end{array}$

te voy a matar. 


$\begin{array}{ccccccc}\text { 95. péro } & \text { sar } & k a & \text { mudar- } & -e ́ & m a & \rightarrow \text { I } \\ \text { pero cómo } & \text { PART. matar } & \text { 2 SING. } & \text { PRON. } & \\ & & \text { FUT. } & & & \text { ACUS. 1 } & \text { SING. }\end{array}$

Pero cómo me vas a matar,

96. $\operatorname{man} s^{-} \quad-i \quad$ man

PRON. ACUS. 1 SING. $\quad$ ser 3 SING. PRON. ACUS. 1 SING. yo tengo

$\begin{array}{lccc}\text { 97. desudúi } & \text { chavrr- } & -e ́ & \rightarrow \text { I } \\ \text { doce } & \text { hijo } & \text { PL. } & \\ \text { doce hijos } & & & \end{array}$

98. $t a \quad m-\quad-i \quad r r o m-\quad$ - $i \quad \rightarrow \mid$ y ADJ. POS.1 SING. FEM. gitano casado FEM. y mi esposa.

$\begin{array}{cccccc}\text { 99. no } \rightarrow 1 & \text { truvúl } & \text { te } & \text { mudar- } & \text {-áu } & \text { to } \\ \text { no } & \text { deber } & \text { NOM. } & \text { matar } & \text { 1SING. } & \text { PRON. } \\ & & & & & \text { ACUS. 2 } \\ & & & & & \text { SING. }\end{array}$

No, te tengo que matar.

ACUS. 2

100. amén ka cher- -á yek apuesta \।। PRON. PERS. PART. FUT. hacer 1 PL. uno apuesta 1 PL.

Vamos a hacer una apuesta.

101. koté s- $-i$ yek pechín bar- $-i \quad \searrow \mid$ 
allí ser 3 SING. uno roca grande FEM. Allí hay una piedra grande.

$\begin{array}{cccccc}\text { 102. kom } & \text { chalav- } & -e ́ l & -a & \text { mai } & \text { zuralé } \\ \text { quien } & \text { golpear } & \text { 3SING. } & \text { SPTB } & \text { más } & \text { fuerte } \\ \text { Quien golpee más fuerte } & & & & \end{array}$

$\begin{aligned} & \text { 103. and } \\ & \text { en ART. DEF. FEM. SING. }\end{aligned}$
en la piedra,

104.ka mudar- él yek aver- é

PART. FUT. matar 3SING. uno otro SICC va a matar al otro.

105.

o rrom phen- él áko $\rightarrow$ I

ART. DEF. gitano casado decir 3SING. bueno MASC. SING.

El gitano dice bueno,

106. pero thiara
pero mañana
pero mañana

107. truvúl te cher- -á $e$ apuesta \। deber NOM. hacer 1 PL. ART. DEF. apuesta tenemos que hacer la apuesta. FEM. SING.

\begin{tabular}{|c|c|c|c|c|c|c|}
\hline $\begin{array}{l}\text { 108. ondaká } \\
\text { entonces }\end{array}$ & $\rightarrow \mid$ & $\begin{array}{c}\text { kána } \\
\text { cuando }\end{array}$ & $\begin{array}{l}l l(e)- \\
\text { ir }\end{array}$ & $\begin{array}{c}-l \\
\text { P. PERF. }\end{array}$ & $\begin{array}{c}-o ́ \\
3 \text { SING. }\end{array}$ & $\begin{array}{l}-t a r \\
\text { REFL. }\end{array}$ \\
\hline
\end{tabular}


109.

ART. DEF. MASC. SING.

el gigante, gigante $\nearrow \mid 1$

gigante

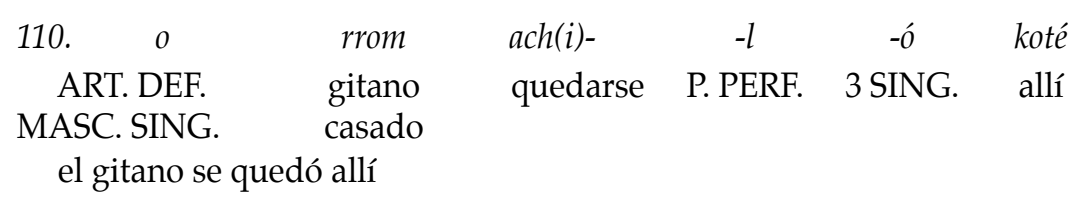
111. kai
donde
0
barr
en la piedra.
ART. DEF. MASC. SING. piedra

112.

vov

akan-

$-d$

$-a ́$

PRON. PERS. 3 SING. MASC. buscar P. PERF. 3 SING.

Él buscó
113. $p$ - $\quad-i \quad$ chéska
ADJ. POS. 3. FEM. cincel
su cincel
114.ta $\quad$ - $\quad-o \quad$ chokáno $\rightarrow 1$
y ADJ. POS. 3 MASC.SING. martillo
y su martillo

$\begin{array}{cccccc}\text { 115. ta } & \text { cher- } & -d & -a ́ & \text { yek } & \text { jiu } \\ \text { y } & \text { hacer } & \text { P. PERF. } & \text { 3 SING. } & \text { uno } & \text { hoyo } \\ \text { e hizo un hoyo } & & & & \end{array}$

116. and

o barr en ART. DEF. MASC. SING. piedra

en la piedra. 


\begin{tabular}{|c|c|c|c|}
\hline vov & tho(v)- & $-d$ & $-a ́$ \\
\hline $\begin{array}{l}\text { PRON. PERS. } 3 \text { SING. MASC. } \\
\text { Él puso }\end{array}$ & poner & P. PERF. & 3 SING. \\
\hline
\end{tabular}

$\begin{array}{lccc}\text { 118. chirál } & \text { ta } & \text { marrnó } & \text { andré } \\ \text { queso } & \mathrm{y} & \text { pan } & \text { dentro }\end{array}$
119. ta uchar- $-d \quad-a ́$ barr \। y tapar P. PERF. 3 SING. ART. DEF. piedra y tapó la piedra. MASC. SING.

\section{0. ondaká $\rightarrow$ I entonces Entonces,}
121. al otrodía av- $\quad$ él $\quad O \quad$ gigante $\rightarrow 1$ al otro día venir 3 SING. ART. DEF. gigante MASC. SING.

al otro día viene el gigante [y le dice:]
122. rrom- -éa $\rightarrow \mid$ ust(i)- -l -án gitano casado VOC. levantarse P. PERF. 2 SING. gitano, ¿te levantaste?

$\begin{array}{lcc}\text { 123. } k a & \text { dikh- } & -a ́ \\ \text { PART. FUT. } & \text { ver } & 1 \text { PL. } \\ \text { Vamos a ver } & & \end{array}$
124. kom ka mudar- -él yek aver- -é \। quien PART. matar 3 SING. uno otro SICC quien va a matar al otro.




125. ondaká $\rightarrow 1$
entonces
Entonces,
126. 0 gigante $d$ - 0 - yek puñete ART. DEF. MASC. gigante dar 3SING. uno puñete SING.
el gigante da un puñete

127. and

o

barr

en $\quad$ ART. DEF. MASC. SING. piedra

en la piedra.
128. mapál $\rightarrow$ o rrom después ART. DEF. MASC. SING. gitano
Después, el gitano
129. d- $-i \quad-a$ yek puñéte $\rightarrow$ ।
dar P. PERF. 3 SING. uno puñete dio un puñete;

$\begin{array}{cccccc}\text { 130. } t a & \text { akan }- & -d & -a ́ & \text { chirál } & \rightarrow 1 \\ \text { y } & \text { sacar } & \text { P. PERF. } & \text { 3SING. } & \text { queso } & \\ \text { y sacó queso } & & & & \end{array}$

131. rrom Vizái \। ART. DEF. MASC. SING. gitano casado inteligente el gitano inteligente.

132. ondaká $\rightarrow$ I
entonces
Entonces,




$\begin{array}{lcccc}\text { 133. } \quad \text { o } & \text { rrom } & \text { phen- } & \text {-él } & \rightarrow \text { I } \\ \text { ART. DEF. MASC. } & \text { gitano casado } & \text { decir } & \text { 3SING. } & \\ \text { SING. } & & & & \\ \text { el gitano dice: } & & & & \end{array}$

$\begin{array}{cccc}\text { 134. sorró } & k a & \text { mang- } & \text {-áu } \\ \text { todo } & \text { PART. FUT } & \text { querer } & \text { 1SING. }\end{array}$

todo lo que yo desee,

135.

tu

$k a$

cher-

PRON. PERS. 2 SING. PART. FUT. hacer 2 SING. tú lo vas a hacer.

136.

me

ni mer-

$-a ́ u \quad \rightarrow 1$

PRON. PERS. 1 SING. NEG. morir 1 SING.

Yo no muero,

137.

$$
\text { me }
$$

s- $\quad$ em zural-

-ó

PRON. PERS. 1 SING. ser 1SING. fuerte MASC.

yo soy fuerte.

138.

$o$

gigante phen-

-él $\rightarrow$ I

ART. DEF. MASC. SING. gigante decir 3 SING.

El gigante dice:

139. so kam- -é $-a$ man- -dar $\nearrow I ।$ que querer 2 SING. SPTB PRON. ACUS. ABLAT. lo que quieras de mí,

1 SING.

140.

me

$k a$

cher-

-áu

PRON. PERS. 1 SING. PART. FUT. hacer 1 SING.

yo lo voy a hacer. 


$\begin{array}{ccccc}\begin{array}{c}\text { 141. áko } \rightarrow 1 \\ \text { bueno }\end{array} & 0 & \text { rrom } & \text { phen- } & \text {-él } \\ \text { ART. DEF. } & \text { gitano } & \text { decir } & \text { 3SING. } \\ \text { MASC. SING. } & \text { casado }\end{array}$

142. tu ka inllar- é

PRON. PERS. PART. llevar 2SING. PRON. ACUS. 1 2 SING. FUT. SING.

tú me vas a llevar

143. yik inchá
hasta allá
hasta allá

144. $k a i \quad s-\quad-i \quad m-\quad$ - $i$ rrom- $\quad-i \quad \rightarrow$ donde ser 3SING. ADJ.POS. FEM gitano FEM. donde está mi esposa, 1 SING.

$\begin{array}{lrcccc}\text { 145. ta } & \text { truvúl } & \text { te } & d- & -e & m a(n) \\ \text { y } & \text { deber } & \text { NOM. } & \text { dar } & \text { 2 SING. } & \text { PRON. ACUS. 1 } \\ \text { y debes darme } & & & & \text { SING. }\end{array}$

$\begin{array}{ccc}\text { 146. yek brécha } & \text { sunakái } & \searrow \text { I। } \\ \text { uno saco } & \text { oro } & \\ \text { un saco de oro. } & & \end{array}$

$\begin{array}{lcc}\begin{array}{l}\text { 147. ondaká } \rightarrow 1 \\ \text { entonces }\end{array} & 0 & \text { gigante } \\ \text { Entonces, el gigante } & \text { ART. DEF. MASC. SING. } & \text { gigante }\end{array}$




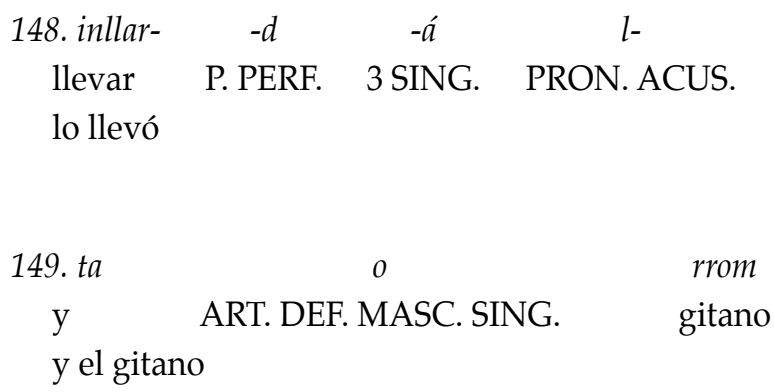

$\begin{array}{cccccc}\text { 150. ach(i)- } & -l & -o ́ & b a r b- & -a l & -o ́ \\ \text { quedar } & \text { P. PERF. } & \text { 3SING. } & \text { riqueza } & \text { ADJ. } & \text { MASC. } \\ \text { quedó rico } & & & & & \end{array}$

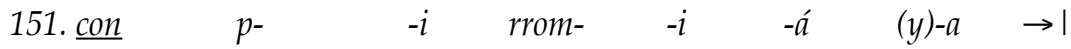
con ADJ.POS. 3 FEM. gitano FEM. SICC INSTR. con su mujer

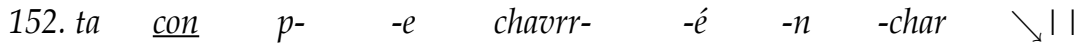

y con ADJ. PL. muchacho SICC PL. INSTR. POS. 3

y con sus hijos.

\section{Conclusiones}

Resumimos aquí algunos aspectos prominentes de la morfología del rromané, visibles en el texto analizado; y explicitamos una posible proyección a partir de este trabajo.

a) El rromané es una lengua que marca morfológicamente las categorías gramaticales de género, número y caso.

- Con respecto a la categoría gramatical de género, en el texto se observa el siguiente contraste: rromorró ${ }^{43}$ ' gitanito' $^{\prime}$ versus rromiorrí ${ }^{44}$ ' gitanita' 
- Con respecto a la categoría gramatical de número, en el texto se observa el siguiente contraste: chavrrós ${ }^{45}$ 'hijo' versus chavrrét6 'hijos'

- Con respecto a la categoría gramatical de caso, algunos ejemplos que se extraen del texto y que muestran estas diferencias en el pronombre personal de primera persona singular son los siguientes:

Me, como en "me sem zuraló"47 'yo soy fuerte', donde la forma " $m e$ " corresponde al pronombre personal de primera persona singular en caso nominativo.

Man, como en "tu ka inllaré man" 48 'tú me vas a llevar', donde la forma "man" corresponde al pronombre personal de primera persona singular en caso acusativo.

Mándar, como en "so kaméa mándar"49 'lo que quieras de mí", donde la forma "mándar" corresponde al pronombre personal de primera persona singular en caso ablativo.

b) En la fórmula tagmémica que se presenta en 2.2.2 se postula un casillero Caso Complementario, el cual es instanciado por el Sufijo Indicador de Caso Complementario (SICC). La función de este morfema, como se indica en Salamanca (2008: 221), es señalar el estatus de complemento (del nombre o del verbo) de la palabra en la que ocurre. En el cuento que nos ocupa, encontramos la palabra "barrénchar"50 'con piedras', donde el sufijo tónico "-é" indica que esta palabra es un complemento (del verbo, en este caso).

c) En la flexión del verbo rromané, se distinguen las categorías gramaticales de "persona / número" y "tiempo / aspecto".

Con respecto al contraste de persona / número, se aprecian en el texto los siguientes casos: 


$$
\begin{aligned}
& \text { peradém }^{51} \text { 'boté' } 1 \text { persona singular (en pretérito perfecto) } \\
& \text { peradán }^{52} \text { 'botaste' } 2 \text { persona singular (en pretérito perfecto) } \\
& \text { peradá }^{53} \text { 'botó' } \quad 3 \text { persona singular (en pretérito perfecto) }
\end{aligned}
$$

Con respecto al contraste de tiempo / aspecto, por su parte, se aprecian en el texto los siguientes casos:

$$
\begin{aligned}
& \text { cheráu }^{54} \text { (cher-ø-áu) 'estoy haciendo' } \\
& \text { cherdá }{ }^{55} \text { (cher-d-á) 'hizo' }
\end{aligned}
$$

En el primer caso, se observa que los morfemas que componen esta palabra son la raíz "cher-" y uno de los alomorfos de primera persona singular: "-au" ${ }^{56}$. Las categorías de tiempo (presente, en este caso) y aspecto (imperfectivo, en este caso) no tienen marca explícita (se instancian, sincréticamente, con el alomorfo "cero").

En el segundo caso, se observa que las categorías de tiempo (pretérito en este caso) y aspecto (perfectivo en este caso) ocurren sincréticamente en el sufijo "-d", pues el sufijo "-a", como vimos en la palabra peradá, corresponde a uno de los alomorfos de tercera persona singular (el otro alomorfo es "-el").

Estas formas de presente y pretérito perfecto, se constituyen en las llamadas formas verbales básicas del rromané, pues a partir de ellas se construyen las formas correspondientes al futuro y pretérito imperfectos, y al pretérito pluscuamperfecto, respectivamente, que son las llamadas formas derivadas.

Un ejemplo, presente en el texto, que ilustra, en parte, lo que hemos dicho en el párrafo precedente, es la palabra "cheréla"57 "(él) hacía estaba haciendo', que se construye con la forma de presente "cherél" 'hace / está haciendo', más un sufijo "-a", cuya función consiste en desplazar el presente (como en este caso) y el pretérito perfecto al pasado, de lo que resulta un pretérito imperfecto ('(él) hacía estaba

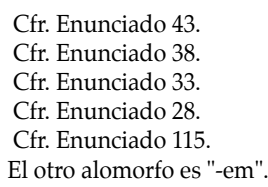


haciendo') y un pretérito pluscuamperfecto ('(él) había hecho'), respectivamente.

Otros ejemplos, presentes en el texto, que ilustran lo que hemos dicho en este punto, son las palabras "inllarél"58 'lleva' e "inllardá"59 'llevó'. En el primer caso, los morfemas que componen esta palabra son la raíz "inllar-", más uno de los alomorfos de tercera persona singular: "-el"60. Al igual que en el caso de "cheráu", las categorías de tiempo (presente, en este caso) y aspecto (imperfectivo, en este caso) se instancian, sincréticamente, con un alomorfo "cero". En el segundo caso, al igual que en "cherdém", se observa que las categorías de tiempo (pretérito en este caso) y aspecto (perfectivo en este caso) ocurren, sincréticamente, en el sufijo "-d".

Por último, debemos señalar que la noción de aspecto que seguimos aquí es la que se propone en Comrie (1976: 5) y que el estatus de aspecto perfectivo o imperfectivo que poseen los tiempos verbales señalados, se establece por el hecho de que sistemáticamente en las formas verbales con aspecto perfectivo ocurre la percepción de la acción verbal como un acto íntegro; mientras que en aquéllos con aspecto imperfectivo, la acción se ve, más bien, como un proceso en evolución o reiteración (Drosdov, 2002: 2).

d) El verbo "tener" en rromané se construye con la forma del verbo ser/ estar / haber, en tercera persona, más un clítico en caso acusativo. En el texto analizado, ocurre el enunciado "...Sáya len but chavrré" 'tenían muchos hijos', donde "sáya" corresponde al pretérito del verbo "ser", en tercera persona; y "len", al clítico acusativo de tercera persona plural.

En el texto también ocurre el enunciado: "...si man desudúi chavrré" '...tengo doce hijos', donde "si" corresponde a la forma del verbo "ser" en tercera persona singular y tiempo presente; y " $m a$ ", al clítico acusativo de primera persona singular.

e) Los sufijos diminutivos afectivos "-orr" e "-ich" muestran la distinción entre morfología temática y atemática. Por ejemplo, en el texto que 
nos ocupa ocurren las palabras rromiorr ${ }^{61}$ 'gitanita' (con el diminutivo temático -orr) y charích ${ }^{62}$ 'carpita' (con el diminutivo atemático ich(a)).

f) Lizarralde y Salamanca (2010) destacan que los demostrativos se construyen con la siguiente fórmula tagmémica:

\begin{tabular}{|l|c|c|c|c|}
\hline \multicolumn{4}{|c|}{ Raíz } \\
\cline { 2 - 4 } & Distancia & Género & Número & \\
\hline g... & $\begin{array}{c}\text { morf. de } \\
\text { distancia }\end{array}$ & $\begin{array}{c}\text { morf. de } \\
\text { género }\end{array}$ & $\begin{array}{c}\text { morf. de } \\
\text { número }\end{array}$ & \multirow{2}{*}{$\ldots a ́$} \\
\end{tabular}

En el texto analizado, encontramos el enunciado "...gayá barí riat" 63 'esta gran noche', en el cual ocurre el demostrativo "gayá" 'ésta'. De acuerdo con el análisis de estos autores, esta palabra se puede segmentar en los siguientes morfemas: una "raíz" discontinua "g-...-a", que señala la deíxis mostrativa; y los afijos -a-, -y- y - - -, que instancian los casilleros de Distancia ('cercanía', en este caso'), Género ('femenino', en este caso) y Número (singular, en este caso), respectivamente.

Hasta aquí el resumen de algunos aspectos prominentes de la morfología del rromané, visibles en el cuento analizado. Con respecto a las proyecciones, un tema que emerge como una posible investigación, a la luz del análisis del texto que nos ocupa, es el de la negación en rromané. En efecto, es interesante constatar la ocurrencia en el cuento de tres marcas de negación (donde en español sólo utilizaríamos una: el adverbio "no"). Consideremos los siguientes enunciados:

Me ni meráu 64 'yo no muero'

(I)nai len charicha ${ }^{65}$ 'no tienen carpita'

¡Na manus! ${ }^{66}$ ‘¡no señor!”

\footnotetext{
Cfr. Enunciado 4.

Cfr. Enunciado 8.

Cfr. Enunciado 2.

Cfr. Enunciado 136.

Cfr.Enunciado 8.

Cfr. Enunciado 45.
} 
Ahora bien, otros textos no analizados aquí muestran otra forma que también indica negación: la palabra "yok". Así, por ejemplo, en el Nuevo Testamento Romané (Sociedad Bíblica, 2007) encontramos el siguiente versículo:

60 A leki dei ppenda: Iok. Vou si te ikkhardol Juan. 'Y su madre respondió: No. Él se llamará Juan'.

Resulta interesante preguntarse cuáles son los factores que están "controlando" la aparición de estas diferentes formas. Por ahora, sólo tenemos hipótesis iniciales, pero, sin duda, constituye un tema particularmente interesante, entre otras cosas, por sus manifiestas diferencias, en este punto, con el español.

Finalmente, es importante destacar que, aunque se observan algunos préstamos del español en los relatos ("con", "pero", "gigante", entre no muchos otros), éstos no constituyen una cantidad prominente, lo cual confirma una de las afirmaciones que hicimos en las páginas iniciales, cual es, que la cultura gitana en general, y su lengua en particular, poseen en Chile una gran vitalidad.

\section{Bibliografía citada}

Comrie, B. (1976). Aspect. Cambridge: Cambridge University Press.

Drosdov, T. (2002). “Gramática del tiempo y el aspecto en ruso y en español". Eslavistica Complutense 2, 33-34.

Elson, B. \& Pickett, V. (1964). An Introduction to Morphology and Syntax. Ciudad de México: Summer Institute of Linguistics.

Gleason, H. (1960). An introduction to descriptive linguistics. New York: Rinehart and Winston.

González, A. \& Salamanca, G. (2001). “Descripción fonológica del romané de Chile". Revista de Filología y Lingüística de la Universidad de Costa Rica XXVII, 177-197.

Grant, A. (1994). Romani: A Conspectus. Notes on Romani Language and Linguistics. Departament of Modern Language, University of Bradford. 
Hancock, I. (1993). Grammar of Vlax Romani. Texas: Romanestan Publications.

Hockett, Ch. (1958). A course in modern linguistics. New York: Macmillan.

Lizarralde, D. \& Salamanca, G. (2010). "Morfología de los Adjetivos Demostrativos en el Rromané Jorajané de Chile". Literatura y Lingüistica 21, 109-126.

Matthews, P. H. (1974). Morphology: an introduction to the theory of wordstructure. Cambridge: Cambridge University Press.

Merrifield, W. (1987). Laboratory manual for morphology and syntax. Dallas: Summer Institute of Linguistics.

Nida, E. (1949[1946]). Morphology. The Descriptive Analysis of Words. Ann Arbor: The University of Michigan Press.

Pickett, V. (1980). Beginning morphology and syntax. Ciudad de México: Summer Institute of Linguistics.

Pike, K. \& Pike, E. (1991). Análisis Gramatical. México: Universidad Nacional Autónoma de México.

Salamanca, G. (2003). Morfología Nominal y Verbal del Romané, lengua de los gitanos de Chile, Tesis para optar al grado de Doctor en Lingüística. Universidad de Concepción.

Salamanca, G. (2004a). “Los gitanos y su lengua”. RLA 42, 63-86.

Salamanca, G. (2004b). "Notas sobre la morfología verbal del rromané, lengua de los gitanos de Chile (1)". Logos 14, 73-96.

Salamanca, G. (2004 2005). “Vitalidad lingüística y cultural en un mundo globalizado: el caso del rromané, frente a las lenguas vernáculas chilenas". Sociedad Hoy 8 9, 107-116.

Salamanca, G. (2006). “Notas sobre la morfología nominal del rromané, lengua de los gitanos de Chile (II)". Alpha 22, 209222.

Salamanca, G. (2008). "Notas sobre la morfología nominal del rromané, lengua de los gitanos de Chile (I)". Literatura y Lingüistica 19, 211-233.

Salamanca, G. \& González, A. (1999). “Gitanos de Chile: Un acercamiento etnolingüístico". Atenea 480, 141-172. 
Salamanca, G. \& Lizarralde, D. (2008). “Propuesta de un grafemario para el rromané jorajané, lengua hablada por los gitanos de Chile (1)". Universum 23, 226-247.

Salamanca, G. \& Rodríguez, Ú. (2009). “Vitalidad del rromané medida de acuerdo a parámetros fonológicos". Universum 24, 182-205.

Samarin, W. (1967). Field Linguistics. A Guide to Linguistic Fieldwork. New York: Holt, Rinehart and Winston.

Sociedad Bíblica Chilena. (2007). Nuevo Testamento Romané. Brasil: Sociedad Bíblica. 